MATEC Web of Conferences 12, 07002 (2014)

DOI: $10.1051 /$ matecconf/ 20141207002

(C) Owned by the authors, published by EDP Sciences, 2014

\title{
Inclined defects and their effect on the fatigue limit and small crack growth
}

\author{
Andrew Roiko,a, Jussi Solin ${ }^{1}$ and Yukitaka Murakami ${ }^{2}$ \\ ${ }^{1}$ VTT Technical Research Centre of Finland, P.O.Box 1000, FI-20044 VTT (Espoo), Finland \\ ${ }^{2}$ Professor Emeritus, Kyushu University, Fukuoka, Japan
}

\begin{abstract}
Small FIB (Focused Ion Beam) milled notches were introduced in quenched and tempered 34CrNiMo6 steel to monitor initiation and growth of cracks in situ. The effect of the defects on the fatigue limit is discussed in terms of the Varea model. Notches with projected $\sqrt{\text { area }}$ of 30 to $56 \mu \mathrm{m}$ normal to the applied stress were inclined by 0,45 , and 60 degrees. The effect of size and inclination on the small crack growth as well as the fatigue limit is discussed.
\end{abstract}

\section{Introduction}

A common feature of high strength steels is the untimely fatigue failure from non-metallic inclusions or defects in the material. A fundamental approach for understanding and modeling effects of these defects is given in the book: Metal Fatigue: Effects of Small Defects and Nonmetallic Inclusion. [1] The largest inclusion in a volume is estimated using statistics of extreme values (SEV). The projected square root area of this inclusion is used together with the microhardness of the steel to predict the fatigue limit $\sigma_{w}$ for the steel using equation:

$$
\sigma_{w}=\frac{C \cdot(H V+120)}{(\sqrt{\text { area } \max })^{1 / 6}}
$$

where $\mathrm{C}$ is a constant that depends on wether the inclusion is on the surface, touching the surface or below the surface. $\mathrm{HV}$ is the microhardness and the $\sqrt{a r e a_{\max }}$ is the largest predicted inclusion in the volume.

This paper focuses on the effect of defects that are not normal to the remote stress, but at an angle and therefore under mixed mode loading. This is the case in many applications experiencing combinations of different modes of loading and/or defect orientations. We examine this problem using experimental data and the $\sqrt{\text { area }}$ parameter.

\section{Method and results}

Wrought quench and tempered steel 34CrNiMo6 with a tensile strength of $1025 \mathrm{MPa}$ with a micro-hardness of HV 373 is used. The fatigue limit of smooth test bars was estimated to be $475 \mathrm{MPa} \pm 11 \mathrm{MPa}$ using the staircase method with a step of $20 \mathrm{MPa}$.

FIB has been successfully utilized in fatigue research. [2-6] For these tests we mill sharp notches in varied angles and sizes leading to identical projected square root areas as shown in Fig. 1.

\footnotetext{
${ }^{\mathrm{a}}$ Corresponding author: andrew.roiko@vtt.fi
}

This is an Open Access article distributed under the terms of the Creative Commons Attribution License 4.0, which permits unrestricted use, distribution, and reproduction in any medium, provided the original work is properly cited. 
Notched specimens were fatigued for $10^{7}$ cycles using tension compression $(\mathrm{R}=-1)$ loading below, at and just above the smooth specimen mean fatigue limit. Cracks were detected at both edges of all notches. They consistently initiated within 20000 cycles, but surface cracks typically arrested before 300000 cycles. Some continued growing, but since the test material contains also inclusions, in many cases the final fracture occurred at an inclusion.

The results can be summarized by noting that the angled notches were less detrimental than the perpendicular ones. An example of this can be seen in Fig. 1. Test bar 2 was remotely broken, while the crack in test bar 1 continued to grow until fracture at a smaller number of cycles.

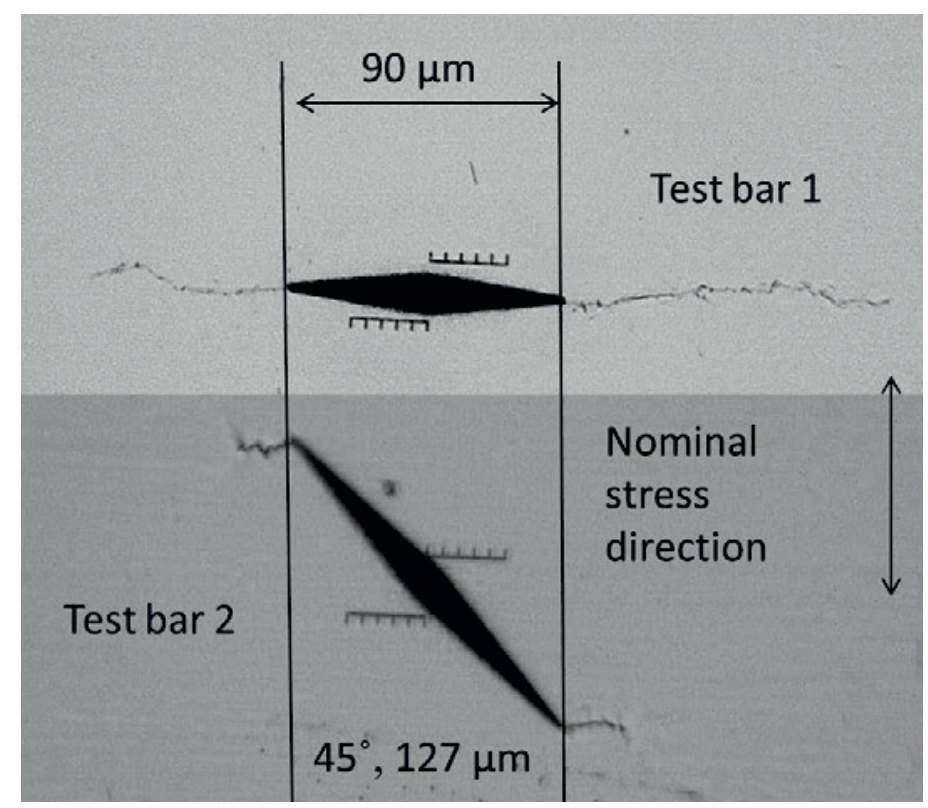

Figure 1. Two notches with the same projected square root area of $56 \mu \mathrm{m}$ failed at $490 \mathrm{MPa}$. The test bar 1 failed from the notch, and test bar 2 failed from another location.

\section{References}

1. Y. Murakami, Metal Fatigue: Effects of Small Defects and Nonmetallic Inclusion. Kyushu University: Elsevier, 2002

2. M. Marx, W. Schäf, H. Vehoff, and C. Holzapfel, Mat.s Sci. and Eng. A, 435-436, pp. 595-601, 2006

3. C. Holzapfel, W. Schäf, M. Marx, Vehoff H., and F. Mucklicha, Scripta. Mat., 56, pp. 697700, 2007

4. Y. Motoyashiki, A. Brückner-Foit, and A. Sugeta, Fat.\& Frac. of Eng. Mat. \& Struc., 30, pp. 556-564, 2007

5. E. Keehana, L. Karlssona, H.K.D.H. Bhadeshiab, and Mattias Thuvandera, Mat. Charac., 59, pp. 877-882, 2008

6. A. Roiko and J. Solin, Inter. J. of Fat., 62, pp. 154-158, 2014 